\title{
Using the Resistivity Imaging Method to Monitor the Dynamic Effects on the Vadose Zone During Pumping Tests at the Pengtsuo Site in Pingtung, Taiwan
}

\author{
Ping-Yu Chang ${ }^{1}$, Shao-Yiu Hsu ${ }^{2, *}$, Liang-Cheng Chang ${ }^{3}$, Wen-Fu Chen ${ }^{4}$, Yu-Wen Chen ${ }^{3}$, \\ and Hsueh-Yu Lu ${ }^{5}$ \\ ${ }^{1}$ Department of Earth Sciences, National Central University, Taoyuan, Taiwan, R.O.C. \\ ${ }^{2}$ Graduate Institute of Hydrological and Oceanic Sciences, National Central University, Taoyuan, Taiwan, R.O.C. \\ ${ }^{3}$ National Chiao Tung University, Hsinchu, Taiwan, R.O.C. \\ ${ }^{4}$ Chia Nan University of Pharmacy and Sciences, Tainan, Taiwan, R.O.C. \\ ${ }^{5}$ National Chung Cheng University, Chiayi, Taiwan, R.O.C.
}

Received 4 January 2015, revised 17 July 2015, accepted 20 August 2015

\begin{abstract}
We conducted a time-lapse monitoring study during a well-pumping test at the Pengtsuo site in Pingtung, Taiwan. Water-level gauges were installed in four wells $(\mathrm{P} 1, \mathrm{~W} 1, \mathrm{O} 1$, and $\mathrm{O} 2)$ at the Pengtsuo site with different screen depths for the observation. We designed the pumping test to be executed in three phases: the background, the stepwise-pumping, and the continuous-pumping phases. The survey line crossed the four wells so that a comparison would be possible between the resistivity measurements and the water-level records. The resistivity differences relative to the pre-pumping background show that electrical resistivity imaging (ERI) can resolve changes due to dewatering from pumping activity. The time-lapse resistivity images reveal that the maximum resistivity increase took place at the locations in the vadose zone instead of at the groundwater surface. The variation in the resistivity differences in the vadose zone correlated to the change in groundwater level in the stepwise phase. On the other hand, the resistivity-difference change was not fully consistent with the groundwater-level change in the continuous-pumping phase. We attribute the abnormal ERI signals to the dynamic non-equilibrium of the water movement in the vadose zone. The findings suggest that pumping designs can affect the changing resistivity differences and water-content distribution patterns. We show the potential of the ER method to reveal both the water flow and water-content changes in the vadose zone with different transient boundary conditions.
\end{abstract}

Key words: Dynamic non-equilibrium effect, Time-lapse resistivity, Transient boundary condtion

Citation: Chang, P. Y., S. Y. Hsu, L. C. Chang, W. F. Chen, Y. W. Chen, and H. Y. Lu, 2016: Using the resistivity imaging method to monitor the dynamic effects on the vadose zone during pumping tests at the Pengtsuo site in Pingtung, Taiwan. Terr. Atmos. Ocean. Sci., 27, 59-71, doi: 10.3319/ TAO .2015.08.20.01(T)

\section{INTRODUCTION}

Water flow in the vadose zone plays a key role in hydrology, ecology, soil science, and agriculture. Information on the constitutive relationship between the capillary pressure and saturation (i.e., the P-S relationship) is critical to the equations governing water flow and transport in the vadose zone. Traditionally, the P-S relationship has been measured in a static condition and treated as a unique function. Experimental studies have recently found that the constitutive relationship is flow-rate dependent under transientconditions (Wildenschild et al. 2001; Hassanizadeh et al. 2002;

\footnotetext{
* Corresponding author

E-mail:syhsu@ncu.edu.tw
}

Diamantopoulos and Durner 2012).

The multistep outflow (MSO) experiment is one of the major methods for presenting the dynamic non-equilibrium of water flows in porous media. Topp et al. (1967) experimentally showed that at a given pressure head, the water contents observed under static or steady-state conditions were smaller than those measured under dynamic conditions. It is possible to quantify the dynamic effects by conducting a comparison between the water-content changes involving a gradual step-by-step increase in the pressure head and the water-content changes involving a one-step increase in the same pressure head (Wildenschild et al. 2001; O'Carroll et al. 2005; Camps-Roach et al. 2010). Sakaki et 
al. (2010) showed that at given water contents, the pressure heads measured under dynamic drainage conditions were statistically smaller than expected from the static capillary curve, but, for the imbibition curves, the dynamic pressure head was higher than that under static conditions. Nevertheless, observations of these dynamic effects on the water flow in porous media have been published only for laboratory studies. The effect of the dynamic non-equilibrium on field-scale water movement during the dewatering is still unclear owing to the challenge of measuring the water content and controlling the pressure-head changes (Diamantopoulos and Durner 2012).

A field-scale multistep experiment requires a systematic approach to controlling both the multistep hydraulic head gradients and the boundary conditions at the field scale. Aquifer analysis commonly involves ground-water pumping tests in which the ground water is continuously withdrawn from a single well or multiple wells. Nwankwor et al. (1992) showed that during a pumping test in an unconfined aquifer, the downward water-table movement would create a vertical hydraulic gradient relative to the water in the drainage zone, and the difference between the static P-S relationship and the dynamic P-S relationship would be significant. By adjusting the pumping rate as well as the water-table level, one can create a series of field-scale hydraulic gradients in the capillary fringe and pre-pumping saturation zones.

Rather than install large numbers of soil-moisture detectors (e.g., time domain reflectometry), researchers have tried to use non-invasive geophysical methods for monitoring subsurface water or contaminant movement (e.g., Daily et al. 1992; Daily and Ramirez 1995; Binley et al. 2002; Gasperikova et al. 2012). Endres et al. (2000) tried to estimate the drained water volume at various times during a pumping test with the "transition-zone drawdown"-distance relationships derived from ground-penetrating radar (GPR) profiles. These researchers discovered that the GPR-estimated volume of drained groundwater was significantly less than the actual pumping volume. Bevan et al. (2003) used GPR to map a water table during a pumping test's dewatering and recovery phase. Electrical resistivity imaging (ERI) is noticeably less popular than GPR for monitoring dewatering and recovery processes during pumping tests because of the slow measurement procedures. The multi-electrode ERI system greatly improved the measurement time and made it possible to use the ERI system to help monitor the changes during the pumping tests. Barker and Moore (1998) used the ERI method to monitor the saturation changes during a four-hour pumping test in an unconfined aquifer. They discovered that a maximum $15 \%$ change in resistivity was centered on the pumping borehole but was asymmetric around the pumping borehole. The findings in Barker and Moore (1998) suggest that the ERI method is a feasible technique for providing alternative information regarding, in particular, the heterogeneity of aquifers for pumping tests.
The pumping activities affect the saturated zone and also the unsaturated zone. The empirical Archie's law has shown that for unsaturated soils with low water content, a slight variation in water content would cause a significant change in the resistivity (Archie 1942). In the empirical Archie's law, the relationship between the Formation Resistivity Index (I) and the degree of water saturation $\left(S_{w}\right)$ is $S_{w}=I^{n}$, where $I=R_{t} / R_{0}, R_{t}$ is the resistivity of the unsaturated soil with $S_{w}, R_{0}$ is the resistivity of the soil saturated with water, and $\mathrm{n}$ is the saturation exponent. Laboratory and field tests indicated that soils with different water content would perform at different variation ranges in bulk resistivity when the soils underwent drying or wetting processes (e.g., Chang et al. 2010; Muñoz-Castelblanco et al. 2012). For nearly saturated soils the same change in water content would result in much smaller resistivity variation than dry unsaturated soils and hence it would be reasonable to expect that the maximum resistivity increase would be in the vadose zone.

We performed two pumping tests, the "stepwise" and "continuous" pumping tests, at the Pengtsuo site in Pingtung, Taiwan to mimic lab-scale MSO experiments. We used an ERI method to examine resistivity variations in the vadose zone during the pumping tests. The pumping strategies provide two transient conditions in the water flow in the unsaturated and pre-pumping saturation zones. As measured according to the ERI method the resistivity variation reflected the water-content changes. Section 2 of this work describes the experimental configuration including the hydrogeology of the testing site and pumping-test settings. In section 3 we present the changes in water level while pumping and observation wells and the results from the measured resistivity variation during the two pumping periods. In section 4 we discuss the observed changes in water content in the vadose zone during the pumping period and link our findings to the lab-scale MSO experimental results. In section 6 we conclude that both the resistivity variation and the dewatering process during the pumping test depend on the pumping rates and the final level of the groundwater table and also on the water-level change rate. This rate-dependent dewatering process might affect the aquifer analysis results.

\section{EXPERIMENT CONFIGURATIONS}

\subsection{Hydrogeology and Pumping-Test Settings}

The current study's observation site is Pengtsuo Elementary School in southwestern Pingtung County, Taiwan. Figure 1 shows the pumping-test experiment configurations. Two observation wells, O1 and O2 (shown in Fig. 1), were installed in 1997 for long-term groundwater-level monitoring. Both the $\mathrm{O} 1$ and $\mathrm{O} 2$ wells have 6" diameters. The O1 well depth reaches $113 \mathrm{~m}$ while the $\mathrm{O} 2$ well depth reaches $210 \mathrm{~m}$ (Table 1). The core logs in Fig. 2 show the records for the first $120 \mathrm{~m}$ of drilling and logging for the $\mathrm{O} 2$ well. From the entire core logs we learned that the sediment at $200 \mathrm{~m}$ 
depth consists of thick, very coarse sand intercalated with coarse sand layers. These thick gravel and sand layers serve as an unconfined aquifer in the Pengtsuo area. The area's groundwater table has a depth of about $5.8 \mathrm{~m}$. Our research team drilled two new shallow wells based on different pumping test strategies, P1 and W1, in 2011 for further testing of the unconfined aquifer's hydraulic properties. P1 is a 10 "diameter, 30-m-deep pumping well and is used as the main

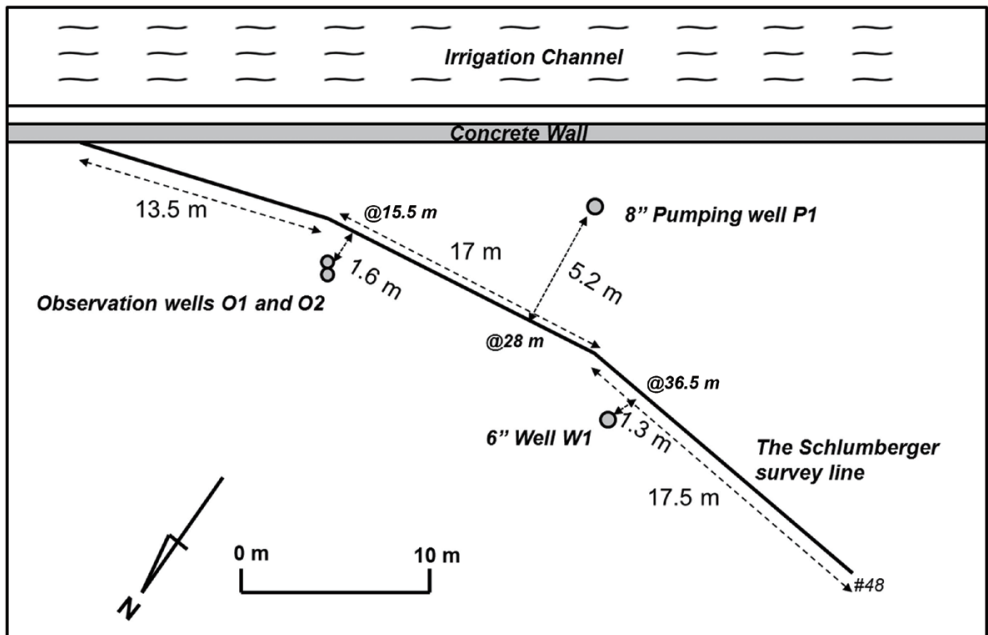

Fig. 1. Schematic diagram of the pumping-test site setup at the Pengtsuo site and the electrical-resistivity survey line configuration.

Table 1. Well configurations at the Pengtsuo site.

\begin{tabular}{ccccc}
\hline Well I.D. & Status & Diameter (inches) & Well Depth $(\mathbf{m})$ & Screen Depth $(\mathbf{m})$ \\
\hline P1 & Pumping & 10 & 30 & $7-30$ \\
W1 & Observation & 8 & 30 & $7-30$ \\
O1 & Observation & 6 & 113 & $83-107$ \\
O2 & Observation & 6 & 210 & $192-204$ \\
\hline
\end{tabular}

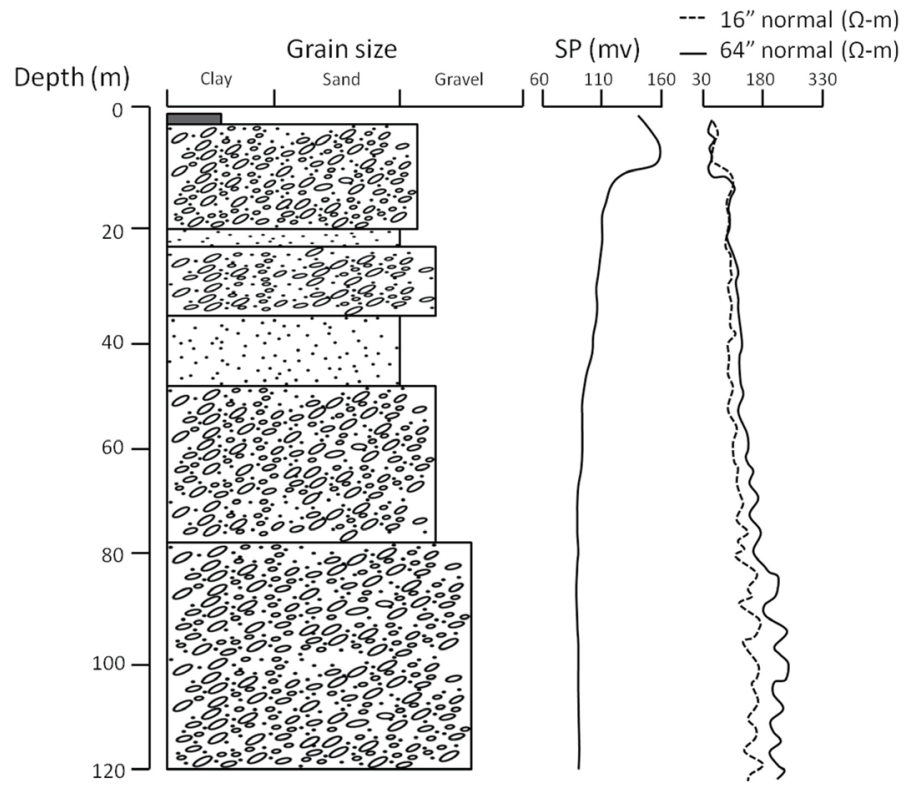

Fig. 2. The drilling logs and logging measurements for the $\mathrm{O} 2$ well. 
pumping well. W1 is located about $3 \mathrm{~m}$ from the P1 well and has an 8 " diameter. Both P1 and W1 have a screen interval between $7-30 \mathrm{~m}$ in depth. The well configurations and pumping-design strategies are shown in Tables 1 and 2. We executed the pumping test in three phases: the background, the stepwise-pumping, and the continuous-pumping phases (Fig. 3). The background groundwater head in the P1 well is $5.998 \mathrm{~m}$ below the ground's surface. In the stepwise-pumping phase we used different strategies with an increasing pumping rate to pump groundwater from $\mathrm{P} 1$. We conducted the first pumping test at a rate of $83.15 \mathrm{~cm} \mathrm{~h}^{-1}$ for about 100 minutes (from 5394 - 5494 minutes). We later increased the pumping rate to $117.41 \mathrm{~cm} \mathrm{~h}^{-1}$ and conducted another test for 266 minutes (from 5494 - 5760 minutes). Owing to a short circuit in the generator, the pumping during the second test stopped for 155 minutes (coming to a stop at 5619 minutes and resuming at 5774 minutes). In this second pumping test in the stepwise phase we increased the pumping rate from $145.63-205.95 \mathrm{~cm} \mathrm{~h}^{-1}$ and proceeded with the test for about 512 minutes (from 5775 - 6286 minutes). After finishing the first experiment phase we turned the pump off for a 529-minute recovery test (from 6286 - 6815 minutes). In the continuous phase the stepwise phase's maximum pumping rate of $205.95 \mathrm{~cm} \mathrm{~h}^{-1}$ was applied to groundwater from P1 for two days (i.e., for a total of about 2902 minutes, from 6831 - 9733 minutes).

\subsection{The Monitoring Configurations for Time-Lapse Resistivity}

Resistivity-imaging surveys involving two-dimensional (2D) surfaces have been widely used in studies on different shallow subsurface wells (e.g., Daily et al. 1992; Griffith and Barker 1993; Cassiani et al. 2006). Because there are many human activities that must take place during stepwise- and continuous-pumping tests, we expected the survey environments to be full of dynamic noises from excess electric fields generated from engines and wires. To reduce the noises and minimize the influences from nearsurface objects, we chose the Schlumberger array for the ERI surveys and avoided installing the survey line through areas where the instruments were piled. Figure 1 shows the ERI-survey configurations. We deployed a 50-m-long

Table 2. Pumping-test design.

\begin{tabular}{|c|c|c|c|}
\hline & Date & Time & Total min. \\
\hline Phase 0 & \multicolumn{3}{|c|}{ Background } \\
\hline Test started on & $05 / 20 / 11$ & $15: 13: 17$ & 0 \\
\hline Test stopped on & $05 / 23 / 11$ & $15: 08: 37$ & 4315 \\
\hline Phase 1-1 & \multicolumn{3}{|c|}{ Stepwise $1^{\text {st }}$ stage pumping } \\
\hline Test started on & $05 / 24 / 11$ & $09: 07: 33$ & 5394 \\
\hline Test stopped on & $05 / 24 / 11$ & $10: 47: 17$ & 5494 \\
\hline Phase 1-2 & \multicolumn{3}{|c|}{ Stepwise $2^{\text {nd }}$ stage pumping } \\
\hline Test started on & $05 / 24 / 11$ & $10: 47: 17$ & 5494 \\
\hline Test stopped on & $05 / 24 / 11$ & $15: 13: 43$ & 5760 \\
\hline Phase 1-3 & \multicolumn{3}{|c|}{ Stepwise $3^{\text {rd }}$ stage pumping } \\
\hline Test started on & $05 / 24 / 11$ & $15: 28: 06$ & 5774 \\
\hline Test stopped on & $05 / 24 / 11$ & $23: 59: 51$ & 6286 \\
\hline Phase & \multicolumn{3}{|c|}{ Recovery } \\
\hline Test started on & $05 / 24 / 11$ & $23: 59: 51$ & 6286 \\
\hline Test stopped on & $05 / 25 / 11$ & 08:49:12 & 6815 \\
\hline Phase & \multicolumn{3}{|c|}{ Continuous } \\
\hline Test started on & $05 / 25 / 11$ & 09:04:41 & 6831 \\
\hline Test stopped on & $05 / 27 / 11$ & $09: 26: 48$ & 9733 \\
\hline
\end{tabular}

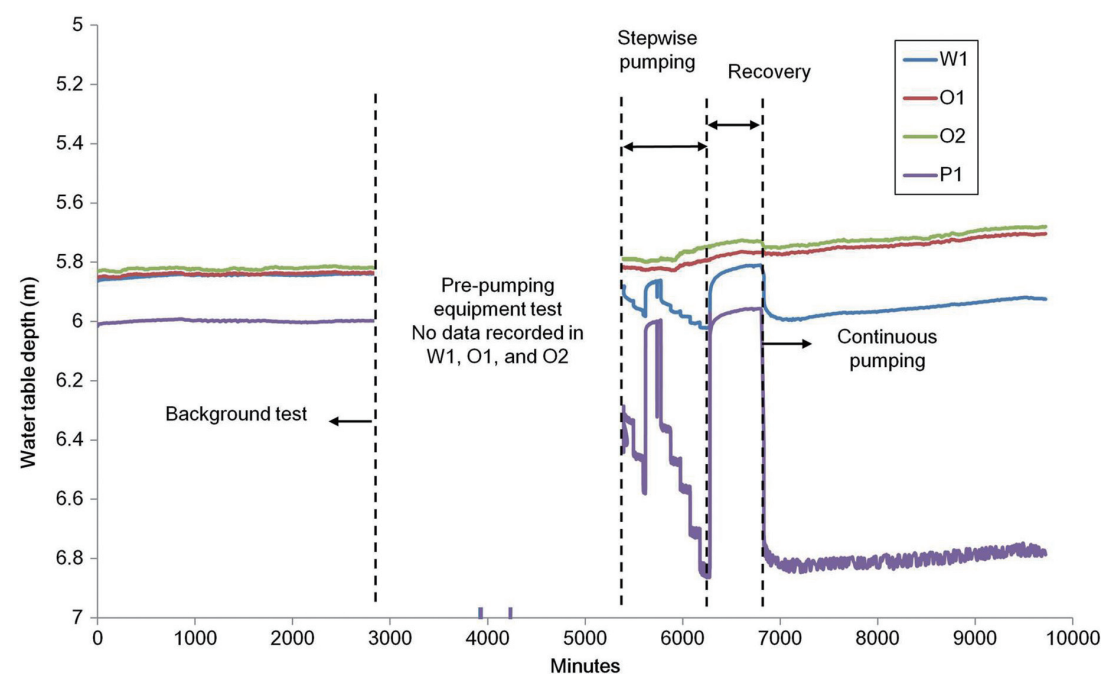

Fig. 3. Water-level variations from the pressure gauges installed in the $\mathrm{O} 1, \mathrm{O} 2, \mathrm{~W} 1$, and $\mathrm{P} 1$ wells during the entire pumping-test period at the Pengtsuo site. (Color online only) 
survey line that came across all four wells: $\mathrm{O} 1, \mathrm{O} 2, \mathrm{P} 1$, and $\mathrm{W} 1$. The $\mathrm{O} 1$ and $\mathrm{O} 2$ wells are located at about the $15.5-\mathrm{m}$ mark on the survey line. The ERI-survey line passes through the space between the $\mathrm{P} 1$ and $\mathrm{W} 1$ wells. The locations of the $\mathrm{P} 1$ and $\mathrm{W} 1$ wells are at the $28-\mathrm{m}$ and $36.5-\mathrm{m}$ marks on the survey line, respectively. Because the electrodes cannot be deployed too close to the pumping wells owing to concerns about heavy pumping and testing activities, we deployed the survey line about $5.2 \mathrm{~m}$ away from the P1 well. The LGM 4-point Light $10 \mathrm{~W}$ resistivity meter and the ActEle system (Lippmann 2005) were used for the field-resistivity measurements. A 1-m electrode interval was chosen for the ERI surveys. We collected two measurements in the background test phase. In the stepwise phase the ERI measurements were collected every 40 - 60 minutes, depending on the quality of each surveys' data.

Although Labrecque et al. (1996) suggested that the errors from repeated measurements may result in underestimated noise levels and that reciprocal measurements can be preferable in accurately representing noise levels, we did not have enough time to collect such information during the dynamic pumping-test experiment in the stepwise- and continuous-pumping phases. The sampling interval was increased gradually in the continuous-pumping phase, extending from the minimum level of about 40 - 60 minutes to the maximum level of about 6 hours at the end of the test. Resistivity data were inverted with EarthImager ${ }^{\mathrm{TM}}$ 2D software (AGI 2006) which employs iterative finite-element algorithms of forward simulation and inversion schemes to estimate sub- surface resistivity structures. Dahlin and Zhou (2004) suggested that robust inversion provides better results in noisy environments than in simple environments. Therefore, we chose to use the robust inversion scheme for the inversion of all time-lapse measurements and to fix the parameters during the inversion processes. The average of the inversion RMS (root mean square) is about $19.3 \%$, which is due chiefly to the field noises from pumping activities and using the 2D inversion scheme for the 3D objects. Factors that can generate noisy measurements in pumping environments include induction in the ground associated with power lines, direct current injection associated with cathodic grounding (Corwin and Hoover 1979), and the metallic casing of a piezometer (Revil et al. 2012). These factors are the possible sources that contribute to noisy measurements and higher RMS in the inversion.

\section{RESULTS}

\subsection{The Background Phase}

We collected two different ERI background phase measurements to check the background variation and the ERI images at the test site. Figures $4 \mathrm{a}$ and $\mathrm{b}$ show two inverted images collected about an hour apart in the background stage. Figure $4 \mathrm{c}$ is the difference between the two background resistivity images. We found sporadic resistive structures with extremely high resistivity (over $1500 \mathrm{Ohm}-\mathrm{m}$ ) located at depths between -1.5 and $-5 \mathrm{~m}$ around the $\mathrm{P} 1, \mathrm{~W} 1, \mathrm{O} 1$ and $\mathrm{O} 2$ wells. We checked the drillers' logs and found that the wells
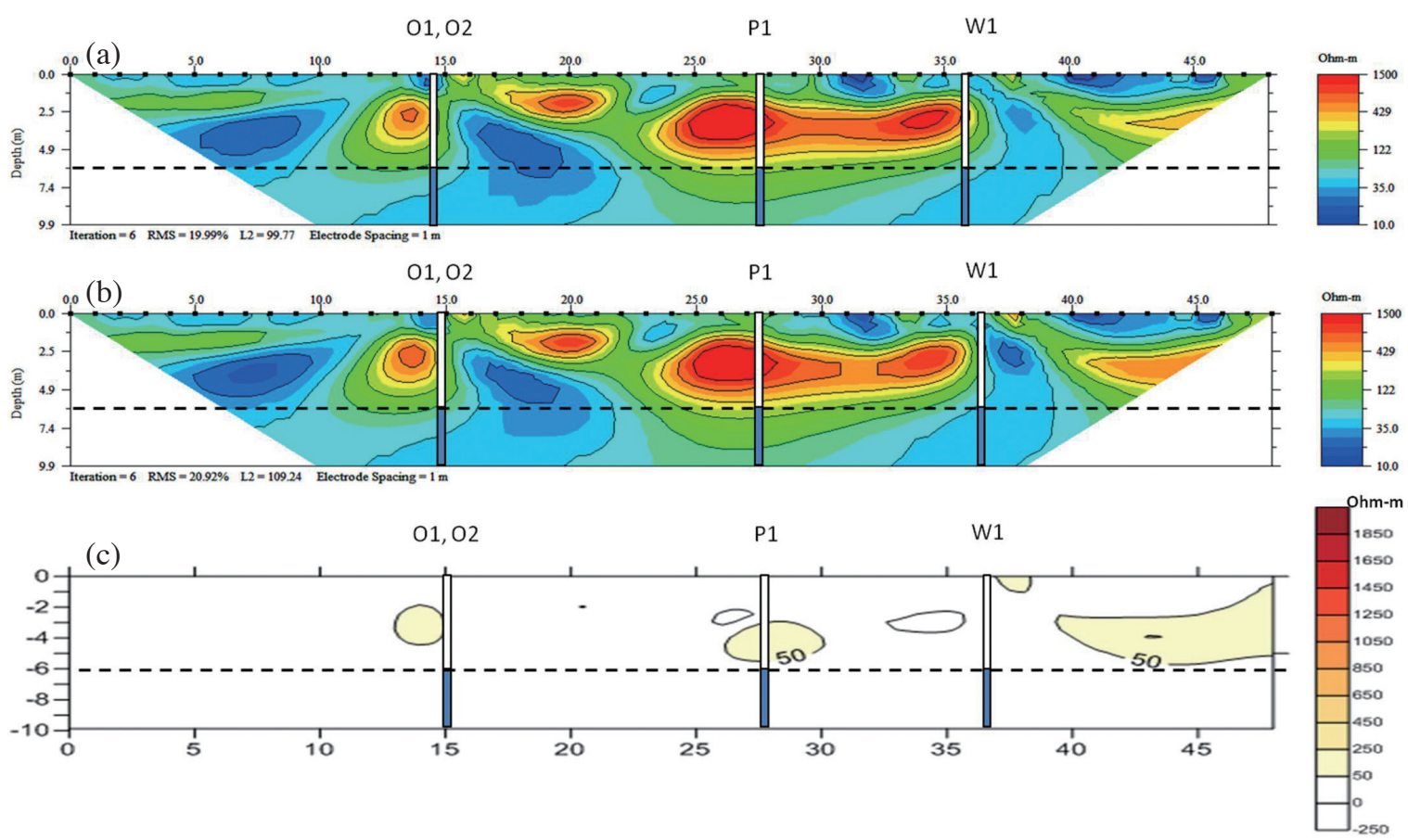

Fig. 4. Two inverted ERI images of the pre-pumping background. Wells O1, O2, W1, and P1 are shown at their projected locations. The dotted line shows the interpolated groundwater table. (Color online only) 
were completed with grouting above the filter pack after the screens were installed to prevent vertical contamination from the surface runoff. Therefore it is probable that grouting cement caused the extremely high resistivity effects in the vadose zone around P1 and $\mathrm{W} 1$, as well as in the old wells $\mathrm{O} 1$ and $\mathrm{O} 2$. In addition, Figs. $4 \mathrm{a}$ and $\mathrm{b}$ show the resistive unsaturated regions were separated by non-vertical, asymmetrical conductive structures that extended from the ground surface at the $15-\mathrm{m}$ and $36-\mathrm{m}$ marks to a greater depth. The conductive structure is likely the electrical resistivity responses of the $\mathrm{O} 1, \mathrm{O} 2$, and $\mathrm{W} 1$ well casings due to the consistency in the well surface locations. Since pumping well P1 was located about $5.2 \mathrm{~m}$ off the resistivity survey line, it is likely that the P1 well effect on the resistivity signal was not significant at the projected location on the resistivity image. We decided to look for differences in resistivity to determine whether or not the time-lapse images could show the variation in water content in different pumping phases. Although the resistivity in the two background images can reach over $1500 \mathrm{Ohm}-\mathrm{m}$ in the vadose zone, the resistivity differences between the two resistivity images are less than $100 \mathrm{Ohm}-\mathrm{m}$ and less than $50 \mathrm{Ohm}-\mathrm{m}$ if only the saturated regions below the groundwater table are considered (Fig. 4c).

We conducted 3D forward simulations and inverted the results with $2 \mathrm{D}$ inversion code to examine the reasons for the asymmetrical resistivity structures and possible error for the 2D inversion for 3D objects. Figures $5 \mathrm{a}$ and $\mathrm{b}$ show the 3D forward simulation models and 2D inverted results for an anomaly located in the straight and banded survey lines. The results show the 3D object can be imaged even it is off the survey line and its footprint resistivity is about 20 - 40\% of the actual 2D image value. Although the banded survey line resistivity image exhibits an asymmetric resistivity anomaly region, the anomaly center location remains the same as the straight line case. We concluded that the asymmetric conductive structure found in the background images

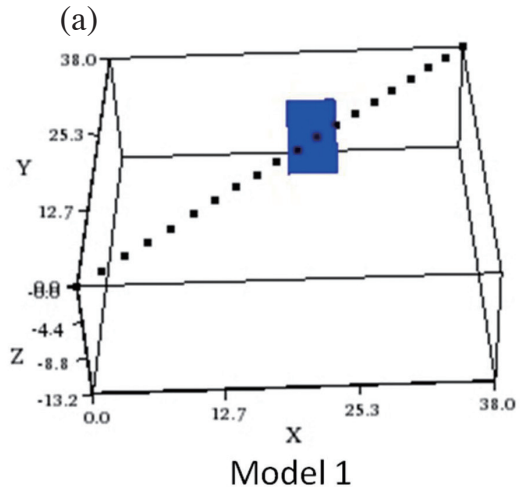

Target: 1000 Ohm-m

Background: $100 \mathrm{Ohm}-\mathrm{m}$

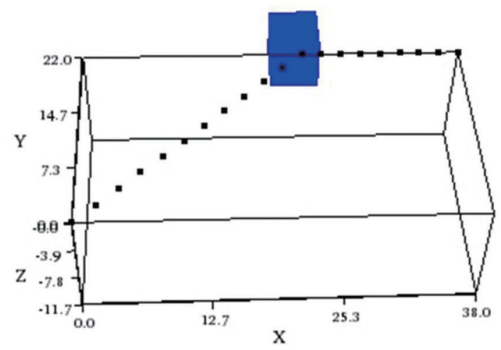

Model 2

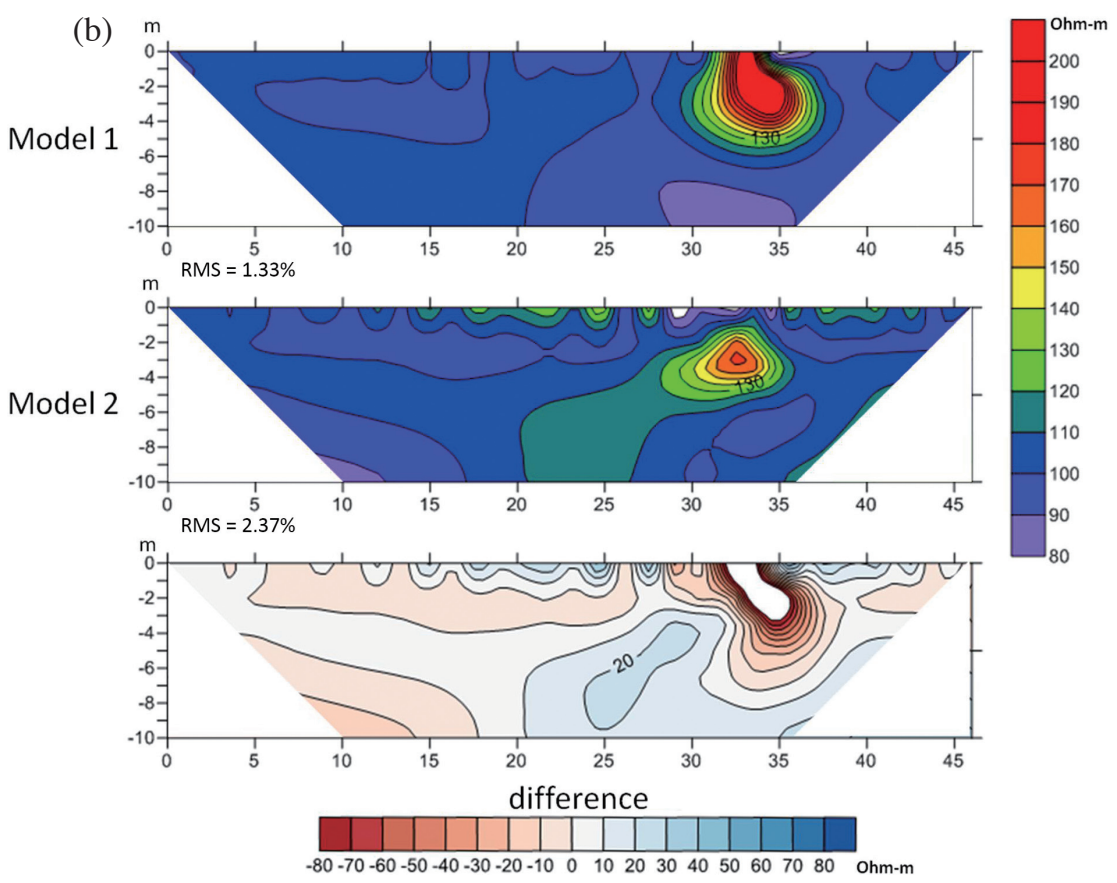

Fig. 5. (a) The 3D model for the forward simulation of the straight and banded geometry for the electrode line. (b) The inverted images of the straight line geometry and banded line geometry, and the resistivity difference of the two inverted images. (Color online only) 
are the responses from the well casing under the influence of banded line geometry. The asymmetric artefacts can be reduced if we take the time-lapse resistivity image difference under the same survey geometry. As a result, we present the time-lapse resistivity difference to the background and only discuss the variation in the maximum resistivity variation in the following sections.

\subsection{The Stepwise-Pumping Phase}

We started tracking the time as soon as we initiated the background monitoring. The stepwise pumping phase started at 5477 minutes and ended at 6278 minutes. To show the effects different pumping activities had on the resistivity variations, we took the resistivity differences between the inverted results during the pumping test and the aver- age inverted resistivity collected in the background phase. Figure 6 shows images of the resistivity change regarding the background-resistivity results during the stepwise-pumping phase. Since we found that the saturated regions had a natural variation less than $50 \mathrm{Ohm}-\mathrm{m}$ in the background phase, we highlighted - in the difference images - where the resistivity increased by over $50 \mathrm{Ohm}-\mathrm{m}$ to identify the regions influenced by dewatering. Figure 6 marks the starting and ending time for the ERT survey since it takes roughly 40 - 50 minutes to complete a survey. The difference can be seen as the average resistivity change for that time period with respect to the pre-pumping background.

One would expect that the maximum increase in resistivity would take place at the pre-pumping groundwater table depth (about $-6 \mathrm{~m}$ ) near the pumping well, as claimed by Barker and Moore (1998). However, according to our
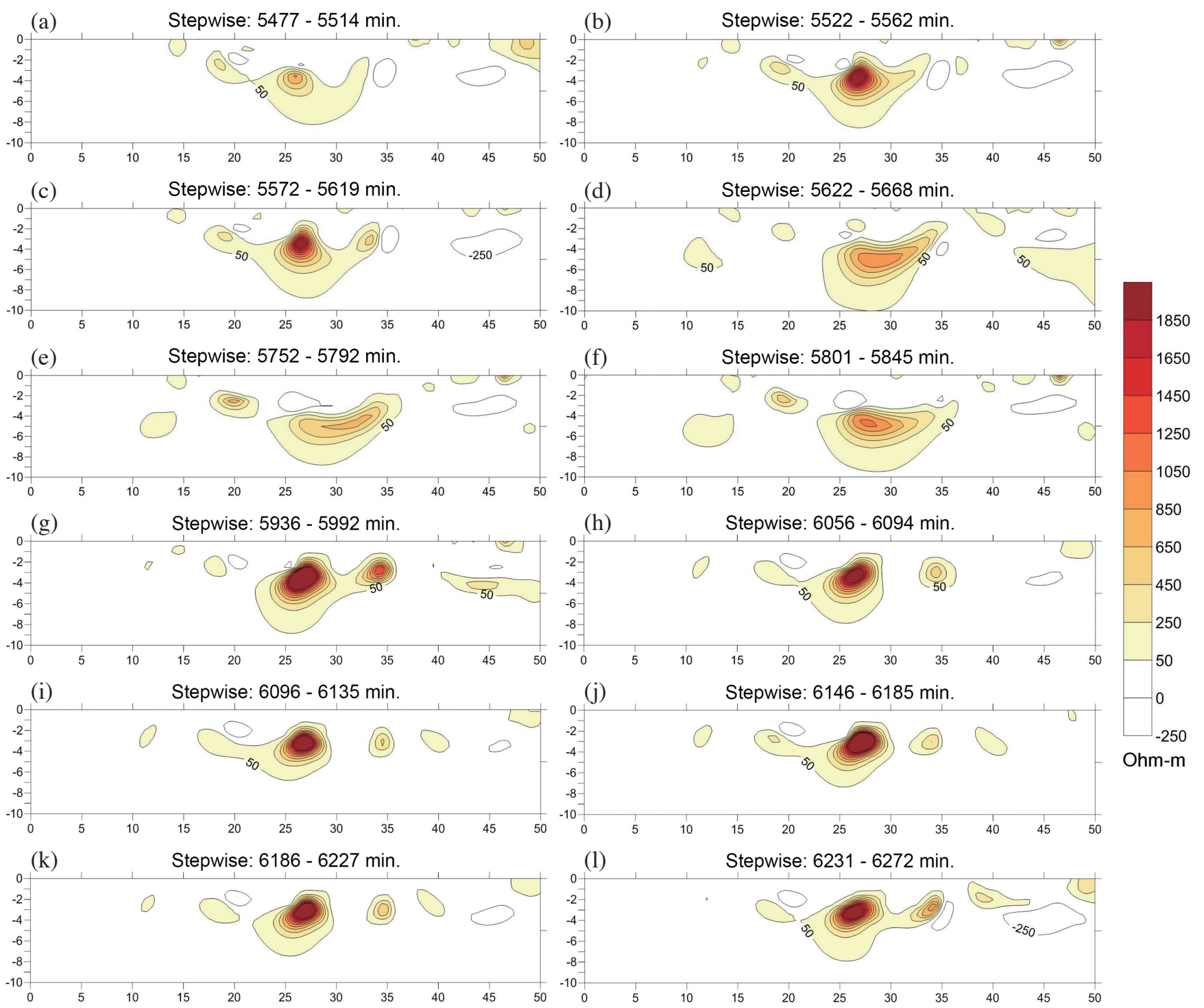

Fig. 6. The resistivity-difference images collected during the stepwise-pumping phase. Noted that images of (d), (e), and (f) were collected during the time when the pump ceased to function. (Color online only) 
findings the difference in images shows that the maximum increase in resistivity occurred above the groundwater table at a depth of $4 \mathrm{~m}$ within the vadose zone soon after the pumping was initiated between 5477 - 5514 minutes, as can be seen in Fig. 6a. A resistive region with resistivity increasing for over $50 \mathrm{Ohm}-\mathrm{m}$ appears right after the pumping was initiated between 5477 - 5514 minutes. The maximum increase in resistivity exceeded $850 \mathrm{Ohm}-\mathrm{m}$ and was located at a depth of $4 \mathrm{~m}$ in this region. The findings are consistent with what we found in the background phase; that is, the resistivity change in the vadose zone is much more sensitive than that in the saturated zone.

The resistive region with resistivity increasing for over $50 \mathrm{Ohm}-\mathrm{m}$ maintained a similar shape and size during the period extending from 5477 - 5619 minutes, as presented in Figs. 6a - c. However, we also observed that the maximum resistivity change increased to over $2000 \mathrm{Ohm}-\mathrm{m}$ at a depth of $4 \mathrm{~m}$ between 5522 and 5619 minutes. It should be noted that a generator problem forced the pumping test to stop for 155 minutes (from 5619 - 5774 minutes). Figure 3 shows that the groundwater table recovered to a depth of about $6 \mathrm{~m}$ between 5619 - 5774 minutes. The difference in images for the period between 5622 - 5668 minutes shows a reduced resistivity-increase value but a more dispersive distribution of the resistive region, as shown in Figs. $6 \mathrm{~d}$ and e. The images collected during the no-pumping period indicate that the change in maximum resistivity declined to slightly over $850 \mathrm{Ohm}-\mathrm{m}$ soon after the pumping stopped, and the region with resistivity increasing for over $850 \mathrm{Ohm}-\mathrm{m}$ seems to have migrated horizontally from the $26.5-\mathrm{m}$ mark to the 32-m mark on the survey line at a depth of $4 \mathrm{~m}$.

The pumping activity in Well P1 resumed at $5775 \mathrm{~min}$ utes, and the pumping rate gradually rose to $145 \mathrm{~cm} \mathrm{~h}^{-1}$, which is $28 \mathrm{~cm} \mathrm{~h}^{-1}$ higher than rate characterizing the period prior to the pump's stoppage. In the last pumping-test stage the pumping rate gradually increased from about $145-206 \mathrm{~cm} \mathrm{~h}^{-1}$ during the period extending from 5775 - 6278 minutes. We found that a region exhibiting increased resistivity appeared again in Fig. 6f; this time between the 26-m and 28-m marks on the survey line at a depth of $4 \mathrm{~m}$ right after the pumping's resumption. As shown in Figs. $6 \mathrm{~g}-1$, the maximum resistivity difference exceeded $2000 \mathrm{Ohm}-\mathrm{m}$ during the second pumping-test stage, which involved much higher pumping rates. We also observed that during the second pumping test from 5936 - 6276 minutes, a small resistive region with resistivity increasing for over $450 \mathrm{Ohm}-\mathrm{m}$ appeared at a depth of $3 \mathrm{~m}$ between the 33-m and 35-m marks on the survey line. The maximum increase in this small region could exceed $1250 \mathrm{Ohm}-\mathrm{m}$ during this period. The same resistive region also appeared shortly between 5572 - 5619 minutes, as shown in Fig. 6c. This resistive region may represent a local heterogeneous soil structure consisting of coarser sediments because the region's reappearance was associated with heavy pumping activities.

\subsection{The Continuous-Pumping Phase}

The stepwise pumping test ended at 6286 minutes and the continuous-pumping test was executed at 6831 minutes with a steady pumping rate of $206 \mathrm{~cm} \mathrm{~h}^{-1}$. The groundwater table recovered between the two phases to the level of $-5.9 \mathrm{~m}$ in P1 and $-5.8 \mathrm{~m}$ in W1. Figure 7 shows the resistivity-difference images collected in the continuous-pumping phase. The resistivity-difference images show that the increases in resistivity peaked during the period between 6870 - 6912 minutes (i.e., right after the pumping was initiated). The region whose resistivity increased to a level exceeding $50 \mathrm{Ohm}-\mathrm{m}$ had a shape similar to the shapes observable in the difference images during the period between 5936 - 6272 minutes in the stepwise phase's second pumping stage (see Figs. $6 \mathrm{~g}-1$ ). Figure 7a shows that the increase of the resistivity exceeded $2000 \mathrm{Ohm}-\mathrm{m}$ during the period between 6870 - $6912 \mathrm{~min}$ utes. Figure $7 \mathrm{~b}$ shows that, after the increases in resistivity peaked, the maximum resistivity difference within the major resistive region decreased to less than $650 \mathrm{Ohm}-\mathrm{m}$ between 6990 - 7072 minutes. Figures 7b - n show that there seems to have been two resistive peaks within the major resistive region whose resistivity increased for over $50 \mathrm{Ohm}$-m after the 6990-minute mark in the continuous-pumping phase. One peak was located at the 26-m mark, and the other at the 34-m mark on the survey line. The former peak is consistent with the location of $\mathrm{P} 1$ and the latter is consistent with the location of the local soil structure identified in the secondpumping stage of the stepwise-pumping phase. A new resistive region whose increase in resistivity exceeded $50 \mathrm{Ohm}-\mathrm{m}$ appeared at a depth of about $3 \mathrm{~m}$ between the $41-\mathrm{m}$ and $45-\mathrm{m}$ marks on the survey line throughout most of the continuouspumping period. The observation W1, located at the 36-m mark on the survey line, seems to have been the structure separating the small resistive region from the major resistive region. Hence, we believe that this small resistive region should be part of the major resistive region.

Most of the differences in images after 7122 minutes in the continuous-pumping stage show that the sizes and shapes of the major resistive regions are similar in Figs. $7 d-n$, except for Figs. 71 and $\mathrm{m}$. The resistive region suddenly condensed into a smaller volume and increases in resistivity declined between 8237 - 8781 minutes (Figs. 71 and m). The regional shower that took place on 26 May (precisely between 7729 - 9159 minutes), with a total rainfall of $87 \mathrm{~mm}$, is the likely reason for the sudden decrease in the vadose zone's resistivity. Unfortunately we did not set up a local weather station and record the exact times of precipitation. Although the water-level records in the wells show that the groundwater table seemingly maintained a quasi-steady state with very little influence from regional showers, the variations in the vadose zone's resistivity suggests that the vadose-zone system was actually influenced by the shower recharge. 


\section{DISCUSSION}

\subsection{Resistivity Difference and Hydraulic Head Difference During the Stepwise Phase}

As noted in the previous section, the resistivity-difference images show that the greatest resistivity variations were in the vadose zone. We discovered that the resistivity differences in the vadose zone were likely correlated with the groundwater-level differences during the stepwise P1 and $\mathrm{W} 1$ pumping tests. Figure 8 presents the relationship between the maximum resistivity variation and the changes in the average groundwater head at wells P1 and W1 during the stepwise-pumping tests. The maximum resistivity changes were consistent with the groundwater-level variations (i.e., the head differences) measured in wells P1 and W1. The groundwater level dropped to the lowest level (about $-6.7 \mathrm{~m}$ and with a $50.6-\mathrm{cm}$ head difference) in P1 at 5596 minutes during the second pumping stage and recovered to its highest level during the period between 5619 - 5774 minutes due to the pump failure. Before the pump failure the maximum resistivity differences at the aforementioned location increased to over $2000 \mathrm{Ohm}-\mathrm{m}$ during the period between $5572-5619$ minutes. When the groundwater head recovered from -6.7 to $-6.0 \mathrm{~m}(2.2-\mathrm{cm}$ head difference) during the period between 5619 - 5774 minutes, the resistivity differences quickly dropped to $730 \mathrm{Ohm}-\mathrm{m}$
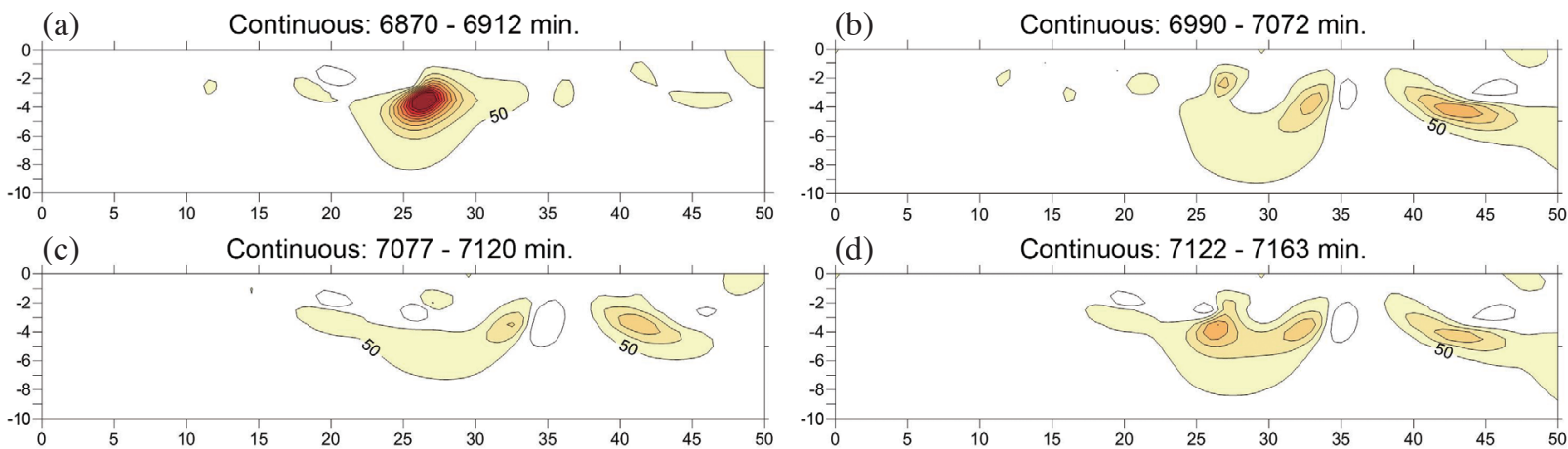

(d) Continuous: $7122-7163 \mathrm{~min}$.

(e)

Continuous: 7172 - 7229 min.
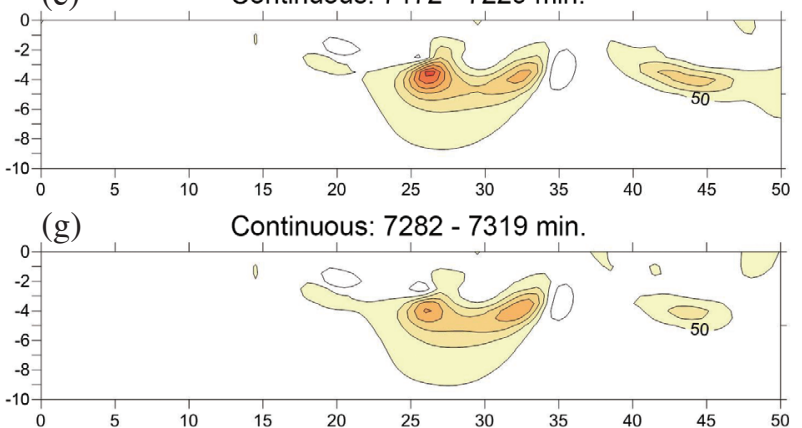

(i)

Continuous: 7402 - 7452 min.
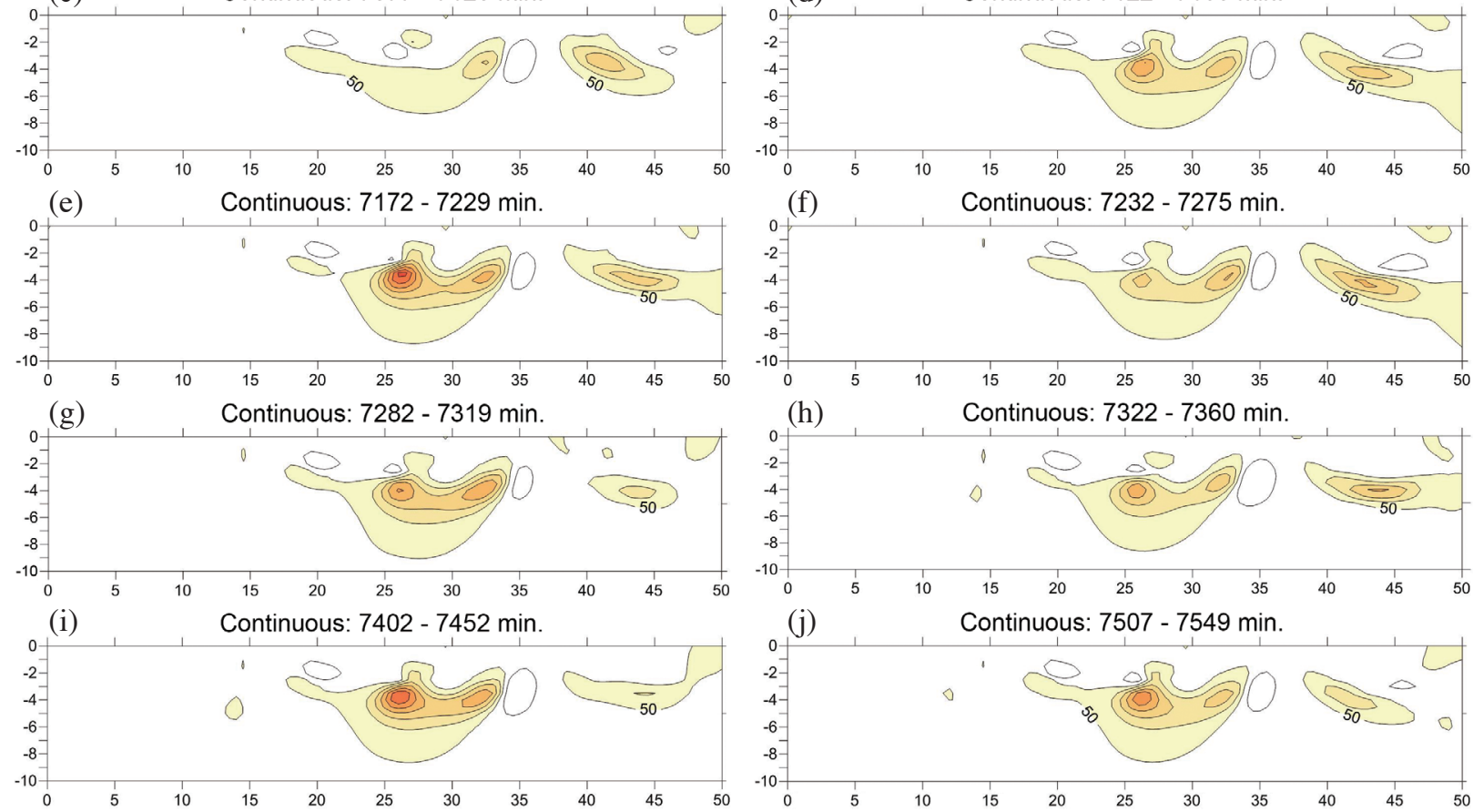

(f) Continuous: $7232-7275 \mathrm{~min}$.

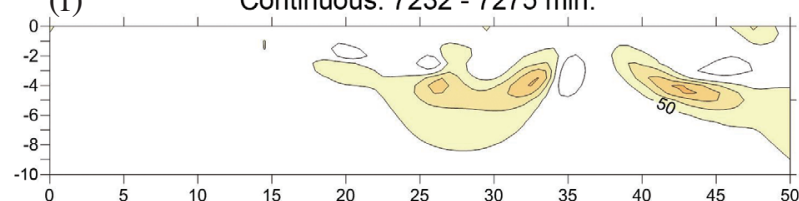

(h) Continuous: $7322-7360 \mathrm{~min}$
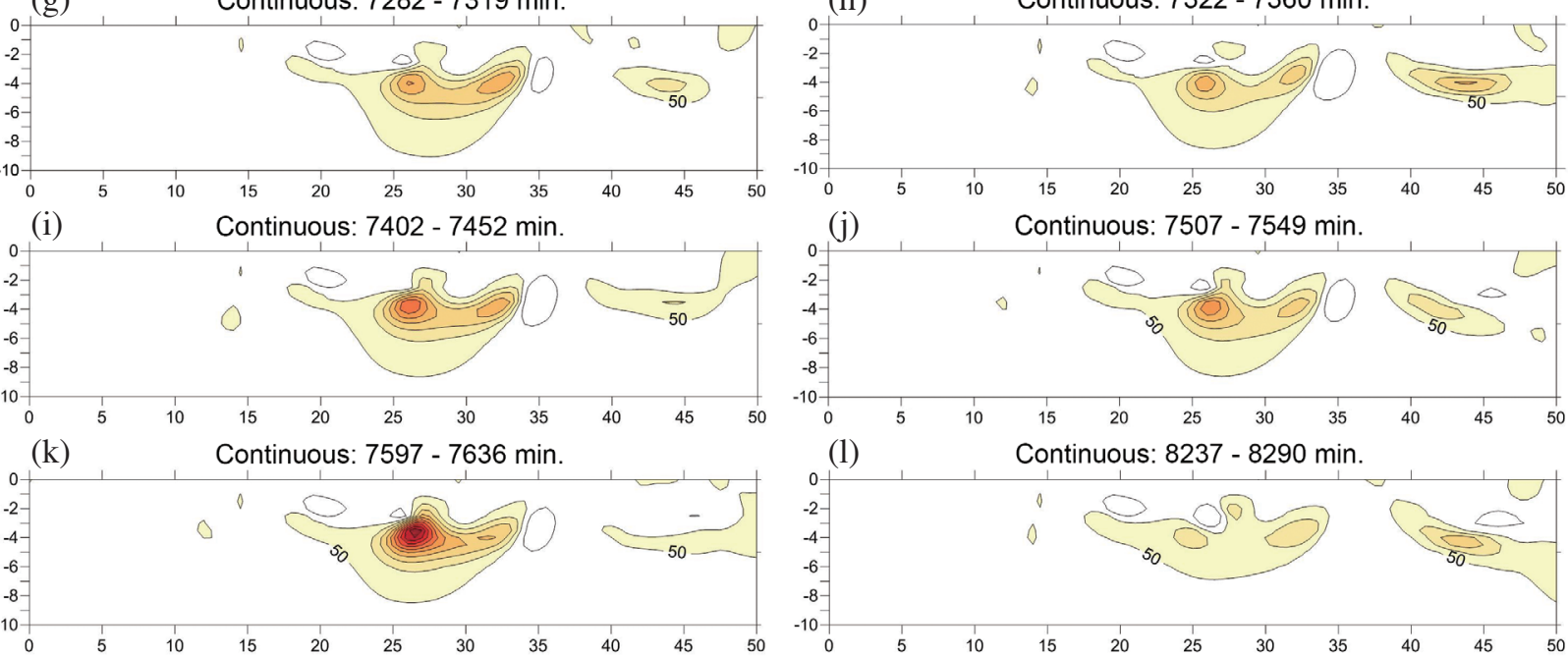

(1) Continuous: 8237 - $8290 \mathrm{~min}$.
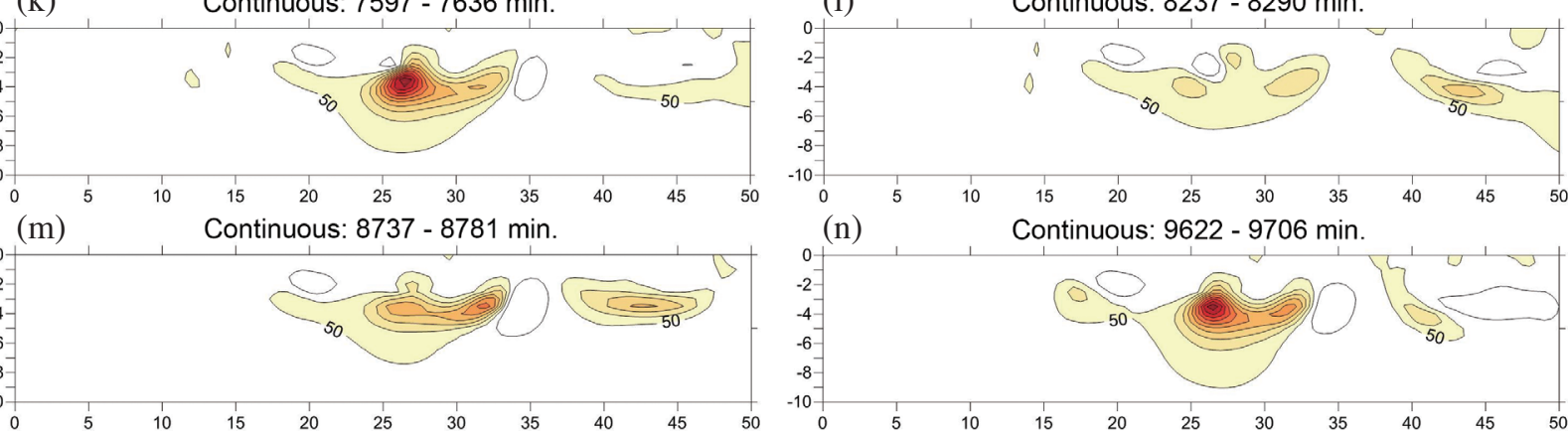

(n) Continuous: 9622 - $9706 \mathrm{~min}$.

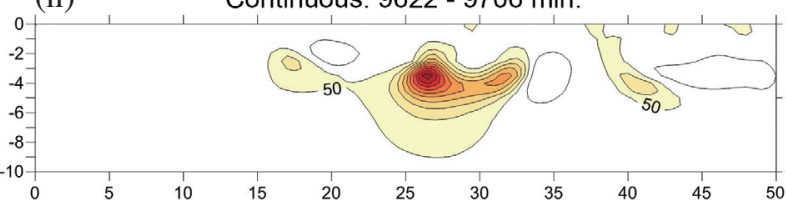

Fig. 7. The resistivity-difference images collected during the continuous-pumping phase. (Color online only) 


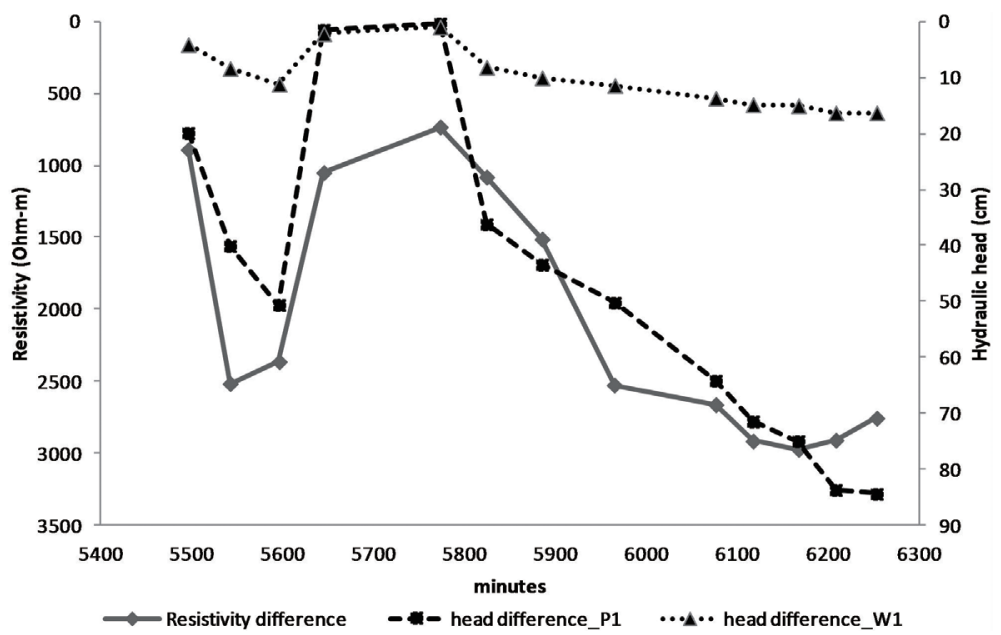

Fig. 8. The maximum resistivity differences versus the hydraulic-head differences measured in wells P1 and W1.

during the recovery period. When the pumping resumed the maximum resistivity difference quickly rose again, this time to $1080 \mathrm{Ohm}-\mathrm{m}$ when the head difference in P1 increased to $36.2 \mathrm{~cm}$. In the final stepwise-pumping test stage with a pumping rate of $205.95 \mathrm{~cm} \mathrm{~h}^{-1}$ and a water table in the pumping well of $-7 \mathrm{~m}$, the maximum resistivity differences went up to $3000 \mathrm{Ohm}-\mathrm{m}$ during the period between 6231 . 6272 minutes.

Figures $9 \mathrm{a}$ and $\mathrm{b}$ show data concerning the maximum resistivity differences and the hydraulic head differences measured in wells P1 and W1, respectively. The relationship between the maximum resistivity differences and the hydraulic-head differences can be described using a log function analogous to the vadose zone's water-retention curve measured in a pumping test conducted by Nwankwor et al. (1992). In the current study the increase in the resistivity difference was strongly related to the decrease in water content during the stepwise phase. The monotonic increase in the resistivity differences implies that the water content in the vadose zone gradually decreased as the hydraulic-head difference increased. In addition, it seems that the resistivity differences in the vadose zone quickly rose to a maximum value owing to the initial pumping, and dropped almost immediately owing to the cessation of pumping without any apparent time lag.

\subsection{Abnormal ERI Signals During the Stoppage and the Continuous-Pumping Test}

During the unexpected stoppage in pumping (5619 5774 minutes), when the water table in the observation and pumping wells (W1, P1) had returned to the pre-pumping level (-5.8 and $-6 \mathrm{~m})$, residual resistivity occurred and declined to around $850 \mathrm{Ohm}-\mathrm{m}$, but dispersed to a deeper area even below the water table, as shown in Figs. $6 \mathrm{~d}$ and e. One phenomenon that possibly explains the abnormal residual resistivity difference is air entrapment.

Laboratory experiments have shown that during the watering process, the air phase can lose its continuity and that air can get trapped in porous media (Smiles et al. 1971; Chatzis and Dullien 1983). In our current study the sudden change in the water table perhaps trapped many air bubbles in the sand layers during the water-recovery period (5619 - 5774 minutes). The trapped air bubbles would have essentially created a temporary unsaturated zone under the water table and caused the residual resistivity difference. The migration of the residual resistivity would likely have been related to the upward movement of the trapped air bubbles. Although air entrapment has been observed in laboratory experiments and considered one of the reasons for the dynamic non-equilibrium flow in porous media (Silliman et al. 2002; Diamantopoulos and Durner 2012), further fieldscale research is necessary to secure direct evidence of the air-bubble entrapment and movement.

During the continuous-pumping test the groundwater level rapidly dropped to about $-6.8 \mathrm{~m}$ and stayed at that level with very little variation from $6870-7636$ minutes. The hydraulic-head difference in P1 and W1 was no difference during the continuous-pumping test as it was during the final stage of the stepwise-pumping test. As expected, the pattern in the resistivity-difference image at the beginning of the continuous-pumping test between 6870 - 6912 minutes as shown in Fig. $7 \mathrm{a}$ is close to the corresponding pattern in the final stage of the stepwise-pumping test between 5936 - $6272 \mathrm{~min}$ utes as shown in Fig. 6i. In addition, the maximum resistivity difference during the continuous-pumping test was less than the corresponding difference during the stepwise-pumping test. This finding implies that under the same hydraulic-head difference the residual water content in the vadose zone was higher during the continuous-pumping test than during the stepwise-pumping test. The residual water content might, in general, depend on the hydraulic head and also on the speed 
of the groundwater level drawdown. This finding would be consistent with MSO experimental results where more water is drained during the stepwise-dewatering process than during the continuous-dewatering process (Topp et al. 1967; O'Carroll et al. 2005; Diamantopoulos and Durner 2012).

After the groundwater level drawdown reached a maximum value $(-7 \mathrm{~m})$, the maximum resistivity difference - rather than increase - started to oscillate, as shown in Figs. $7 b$ - j even though the head differences in P1 and W1 were relatively stable. The unsteady ERI signal between 6912 - 7636 minutes, as shown in Figs. 7c, d, and e, implies a continuous change in water content in the vadose zone during that period. Water redistribution is a possible explanation for the variations in water content during the continuous-pumping test.

Previous research involving MSO experiments has shown that during drainage some water can get trapped in the form of disconnected pendular rings and slowly move toward continuous water bodies (Poulovassilis 1974). This slow residual water movement can continue for periods of hours or even days after the hydraulic pressure head has reached equilibrium state (Topp et al. 1967). Wildenschild et al. (2001) proposed that soil near flow outlets can drain faster than the upper part of the soil, retarding the whole drainage process. The quick drop in groundwater level in the continuous phase might cause the water in the pre-pumping saturated zone to move faster than the water in the capillary fringe zone. In our current study the dynamic dewatering process in the saturated zone caused a jump in the resistivity difference at the beginning of the pumping test between 6870 - 6912 minutes. The movement of disconnected water then led to a watercontent change in the vadose zone, causing the variation in the resistivity difference between $6912-7636$ minutes.

\section{CONCLUSIONS}

We used the ERI method in this study to monitor water-content changes in the vadose zone during different well-pumping tests at the Pengtsuo site in Pingtung, Taiwan. The pumping tests were executed in three different phases: the background phase, the stepwise phase and the continuous phase. The resistivity survey line crossed four wells, permitting a rigorous comparison of the resistivity measurements with the water-level records. The previous records in the area led us to originally expect that the pumping would cause a drawdown of $2 \mathrm{~m}$ for the groundwater level. However, the changes in the groundwater heads during the entire study were less than $1 \mathrm{~m}$. According to the time-lapse resistivity images, the maximum increases in resistivity took place at vadose-zone locations instead of at the pre-pumping groundwater table in the time-lapse resistivity images. The significant variations in resistivity differences show that the vadose zone was very sensitive to the pumping activity even if the changes in the groundwater table were insignificant.

The variations in resistivity differences were significantly different during the stepwise and continuous phases. The increase in the resistivity differences is well correlated to the increase in water-level drawdown during the stepwisepumping test. However, the change in resistivity differences varied for more than 700 minutes (6870 - 7636 minutes). We attribute the discrepancy in the resistivity difference variations during two pumping phases to dynamic water flow non-equilibrium in the unsaturated soil. Furthermore, it seems that the resistivity differences in the vadose zone quickly rose to a maximum value owing to the initial pumping and dropped almost immediately owing to the pumping cessation during the stepwise-pumping phase.

So that hydrologists can quantitatively express the dynamic water flow non-equilibrium in the field, researchers must conduct careful, sophisticated analyses of both the resistivity-difference changes during the two types of pumping phases and the relationship between the resistivity difference and water content. The resistivity difference
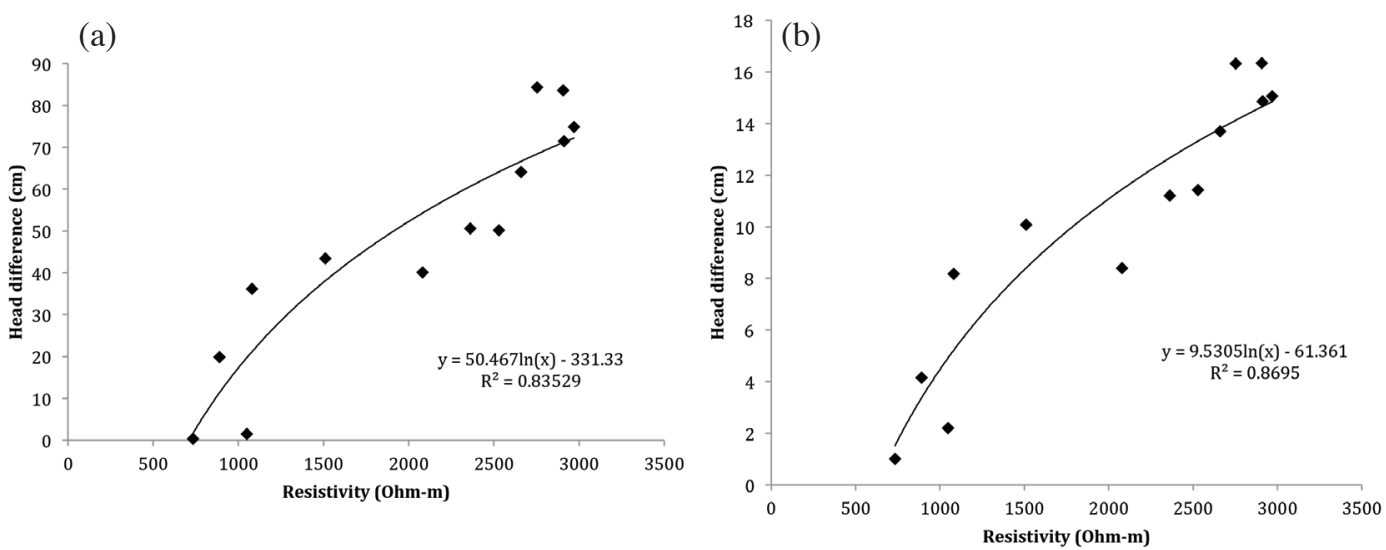

Fig. 9. Variations in the maximum resistivity difference and the head difference for the P1 and W1 wells during (a) the stepwise-pumping phase and (b) the continuous-pumping phase. 
mechanism and its migration are not well understood, but experiments like the ones we propose here have great potential in applying the ERI method to vadose zone water movement field-scale dynamic observations. We are currently examining the data on resistivity differences and relative water-level differences in the hopes of rigorously calculating resistivity-related transmissivity and specific yields.

Acknowledgements Our research team collected the data for this study during pumping tests executed by the Central Geological Survey (CGS) of Taiwan. We are encouraged to release the raw data under an agreement with CGS of Taiwan. The inverted data can be acquired freely. For more information simply contact Dr. Chang, Ping-Yu via email (pingyuc@gmail.com). This study was funded by the Central Geological Survey, MOEA, R.O.C. We are grateful for the help from the pumping-test engineers at the Taiwan Sugar Company.

\section{REFERENCES}

AGI, 2006: Instruction Manual for EarthImager 2D ver. 2.3.01. Austin, Texas, Advanced Geosciences, Inc.

Archie, G. E., 1942: The electrical resistivity log as an aid in determining some reservoir characteristics. Trans. AIME, 146, 54-62, doi: 10.2118/942054-G. [Link]

Barker, R. and J. Moore, 1998: The application of time-lapse electrical tomography in groundwater studies. The Leading Edge, 17, 1454-1458, doi: 10.1190/1.1437878. [Link]

Bevan, M. J., A. L. Endres, D. L. Rudolph, and G. Parkin, 2003: The non-invasive characterization of pumpinginduced dewatering using ground penetrating radar. J. Hydrol., 281, 55-69, doi: 10.1016/S0022-1694(03)00200-2. [Link]

Binley, A., G. Cassiani, R. Middleton, and P. Winship, 2002: Vadose zone flow model parameterisation using crossborehole radar and resistivity imaging. J. Hydrol., 267, 147-159, doi: 10.1016/S0022-1694(02)00146-4. [Link]

Camps-Roach, G., D. M. O'Carroll, T. A. Newson, T. Sakaki, and T. H. Illangasekare, 2010: Experimental investigation of dynamic effects in capillary pressure: Grain size dependency and upscaling. Water Resour. Res., 46, W08544, doi: 10.1029/2009WR008881. [Link]

Cassiani, G., V. Bruno, A. Villa, N. Fusi, and A. M. Binley, 2006: A saline trace test monitored via timelapse surface electrical resistivity tomography. $J$. Appl. Geophys., 59, 244-259, doi: 10.1016/j.jappgeo.2005.10.007. [Link]

Chang, P. Y., T. Y. Yang, L. L. Chyi, and W. L. Hong, 2010: Electrical resistivity variations before and after the Pingtung earthquake in the Wushanting mud volcano area in southwestern Taiwan. J. Environ. Eng.
Geophys., 15, 219-231, doi: 10.2113/JEEG15.4.219. [Link]

Chatzis, I. and F. A. L. Dullien, 1983: Dynamic immiscible displacement mechanisms in pore doublets: Theory versus experiment. J. Colloid Interface Sci., 91, 199222, doi: 10.1016/0021-9797(83)90326-0. [Link]

Corwin, R. F. and D. B. Hoover, 1979: The self-potential method in geothermal exploration. Geophysics, 44, 226-245, doi: 10.1190/1.1440964. [Link]

Dahlin, T. and B. Zhou, 2004: A numerical comparison of $2 \mathrm{D}$ resistivity imaging with 10 electrode arrays. Geophys. Prospect., 52, 379-398, doi: 10.1111/j.13652478.2004.00423.x. [Link]

Daily, W. and A. Ramirez, 1995: Electrical resistance tomography during in-situ trichloroethylene remediation at the Savannah River Site. J. Appl. Geophys., 33, 239249, doi: 10.1016/0926-9851(95)90044-6. [Link]

Daily, W., A. Ramirez, D. LaBrecque, and J. Nitao, 1992: Electrical resistivity tomography of vadose water movement. Water Resour. Res., 28, 1429-1442, doi: 10.1029/91WR03087. [Link]

Diamantopoulos, E. and W. Durner, 2012: Dynamic nonequilibrium of water flow in porous media: A review. Vadose Zone J., 11, doi: 10.2136/vzj2011.0197. [Link]

Endres, A. L., W. P. Clement, and D. L. Rudolph, 2000: Ground penetrating radar imaging of an aquifer during a pumping test. Ground Water, 38, 566-576, doi: 10.1111/j.1745-6584.2000.tb00249.x. [Link]

Gasperikova, E., S. S. Hubbard, D. B. Watson, G. S. Baker, J. E. Peterson, M. B. Kowalsky, M. Smith, and S. Brooks, 2012: Long-term electrical resistivity monitoring of recharge-induced contaminant plume behavior. J. Contam. Hydrol., 142-143, 33-49, doi: 10.1016/j. jconhyd.2012.09.007. [Link]

Griffith, D. H. and R. D. Barker, 1993: Two-dimensional resistivity imaging and modelling in areas of complex geology. J. Appl. Geophys., 29, 211-226, doi: 10.1016/0926-9851(93)90005-J. [Link]

Hassanizadeh, S. M., M. A. Celia, and H. K. Dahle, 2002: Dynamic effect in the capillary pressure-saturation relationship and its impacts on unsaturated flow. Vadose Zone J., 1, 38-57, doi: 10.2136/vzj2002.3800. [Link]

Labrecque, D. J., M. Miletto, W. Daily, A. Ramirez, and E. Owen, 1996: The effects of noise on Occam's inversion of resistivity tomography data. Geophysics, $\mathbf{6 1}$, 538-548, doi: 10.1190/1.1443980. [Link]

Lippmann, E., 2005: Four-point light hp technical data and operating instructions ver. 3.37. Lipmann Geophysikalische Messgeräte, Schaufling, Germany, 28 pp.

Muñoz-Castelblanco, J. A., J. M. Pereira, P. Delage, and Y. J. Cui, 2012: The influence of changes in water content on the electrical resistivity of a natural unsaturated loess. Geotech. Test. J., 35, 11-17.

Nwankwor, G. I., R. W. Gillham, G. van der Kamp, and F. 
F. Akindunni, 1992: Unsaturated and saturated flow in response to pumping of an unconfined aquifer: field evidence of delayed drainage. Ground Water, 30, 690700, doi: 10.1111/j.1745-6584.1992.tb01555.x. [Link]

O'Carroll, D. M., T. J. Phelan, and L. M. Abriola, 2005: Exploring dynamic effects in capillary pressure in multistep outflow experiments. Water Resour. Res., 41, W11419, doi: 10.1029/2005WR004010. [Link]

Poulovassilis, A., 1974: The uniqueness of the moisture characteristics. Eur. J. Soil Sci., 25, 27-33, doi: 10.1111/j.1365-2389.1974.tb01099.x. [Link]

Revil, A., M. Karaoulis, T. Johnson, and A. Kemna, 2012: Review: Some low-frequency electrical methods for subsurface characterization and monitoring in hydrogeology. Hydrogeol. J., 20, 617-658, doi: 10.1007/ s10040-011-0819-x. [Link]

Sakaki, T., D. M. O'Carroll, and T. H. Illangasekare, 2010: Direct quantification of dynamic effects in capillary pressure for drainage-wetting cycles. Vadose Zone J.,
9, 424-437, doi: 10.2136/vzj2009.0105. [Link]

Silliman, S. E., B. Berkowitz, J. Simunek, and M. T. van Genuchten, 2002: Fluid flow and solute migration within the capillary fringe. Ground Water, 40, 76-84, doi: 10.1111/j.1745-6584.2002.tb02493.x. [Link]

Smiles, D. E., G. Vachaud, and M. Vauclin, 1971: A test of the uniqueness of the soil moisture characteristic during transient, nonhysteretic flow of water in a rigid soil. Soil Sci. Soc. Am. J., 35, 534-539, doi: 10.2136/ss saj1971.03615995003500040018x. [Link]

Topp, G. C., A. Klute, and D. B. Peters, 1967: Comparison of water content-pressure head data obtained by equilibrium, steady-state, and unsteady-state methods. Soil Sci.Soc. Am. J., 31, 312-314, doi: 10.2136/sssaj1967.0 3615995003100030009x. [Link]

Wildenschild, D., J. W. Hopmans, and J. Simunek, 2001: Flow rate dependence of soil hydraulic characteristics. Soil Sci. Soc. Am. J., 65, 35-48, doi: 10.2136/ sssaj2001.65135x. [Link] 